\title{
Laboratory Kit for Oscillometry Measurement of Blood Pressure
}

\author{
Jan Dvořák, Jan Havlík \\ Department of Circuit Theory \\ Faculty of Electrical Engineering, Czech Technical University in Prague \\ Technická 2, CZ-16627 Prague 6 \\ dvoraj45@fel.cvut.cz,xhavlikj@fel.cvut.cz
}

\begin{abstract}
This paper presents a laboratory kit for oscillometry blood pressure measurement. The laboratory kit was designed for research purposes in the field of medical technology. The presented device allows to show not only the calculated results (such as systolic and diastolic blood pressure and the heart rate) as standard devices, but also the raw signals. It means there is a possibility to study the impact of set-up parameters and other factors on the measured values.
\end{abstract}

Keywords: blood pressure, oscillometry, laboratory kit.

\section{Introduction}

The blood pressure measurement is a commonly used method for monitoring of cardiac system condition. It is used in both hospital and home care. The most commonly used method is non-invasive oscillometry based on evaluation of amplitude envelope of the oscillations in the sphygmomanometer cuff. Today, this method is the standard method for automated blood pressure measurement.

For the full comprehension of the principle, it is necessary to study the sensing techniques, plethysmographic signal and the methods used for signal processing. Standard blood pressure meters are designed as devices able to display only the systolic (SBP) and diastolic (DBP) arterial pressure and the heart rate. Blood pressure meters built in more complex devices such as monitors of vital functions are often able to display also the plethysmographic curve and mean arterial pressure (MAP). Unfortunately, there is no chance of displaying the inner signals needed for comprehension of the function such as raw signals from the pressure sensor and signals in the processing path.

The auscultatory method based on the auscultation of Korotkoff sounds is predominant for clinical measurement. Despite all its advantages, this method is hard to automate.

Due to the described features of standard blood pressure meters, a new laboratory kit has been designed. This kit allows us to monitor all crucial signals and values in real time and records them to a PC for future processing. It is primarily designed for 
oscillometry measurement, but it can be a very useful tool for measurement using the auscultatory method as well. The device allows manual control of inflating and deflating, display on the board shows actual pressure in the cuff.

The designed oscillometer provides the whole pressure curve, not only the SBP and DBP values as a standard blood pressure device. From the acquired signals, it is also possible to count the hemodynamic parameters such as augmentation index (AI) or pulse wave velocity (PVW), which is very important for determination of vascular system condition.

The processing of oscillometric signals is not yet standardized. It means each blood pressure device could provide slightly different results for the same patient at the same time. Without knowledge of the whole signal (pressure curve, occurence of artifacts etc.) there is no chance to select the correct result corresponding to real values.

\section{Methods}

The main task is to design and to realize the laboratory kit that allows development of robust signal processing algorithms that are not susceptive to artifacts (such as moving artifacts). For easy understanding of blood pressure measurement with oscillometry method, it is important to know the mean pressure in the cuff, the corresponding amplitude of oscillations, the basic principles of measured signals processing and the calculation of required values, and finally the effect of hardware set-up parameters.

The most interesting signals are the mean pressure in the cuff and the corresponding oscillations. Monitoring of these signals is impossible when utilizing standard devices. The designed laboratory kit has to allow both direct monitoring of the signals using an oscilloscope and recording of the signals to a PC for future processing.

The process of oscillometry measurement is very simple. The control valve is closed and the cuff is inflated to a pressure in excess of the systolic arterial pressure with an air pump. Then the control valve is slightly released and the pressure reduces to values below diastolic pressure. It takes about 40 seconds.

Inflating and deflating of the cuff is controlled by a microprocessor. The processor also secures analog-to-digital conversion and calculations of required values. Firstly, measured signal is processed by peak detector. From the amplitudes of the oscillations at any point in time there is derived an envelope of maxims and minims. The point of maximum amplitude of oscillations is when the underlying pressure in the cuff corresponds to mean arterial pressure. Systolic pressure is determined from the data already acquired. SBP can be determined by selecting the underlying pressure that corresponds to the amplitude of 55\% of the maximum amplitude of oscillations (MAP) before the point of MAP. Furthermore, DBP is the underlying pressure when the envelope of oscillations has decreased to $85 \%$ of the maximal amplitude as shown on the Figure 1. Finally, the processor may calculate the heart rate from average distances between the peaks of oscillations. 


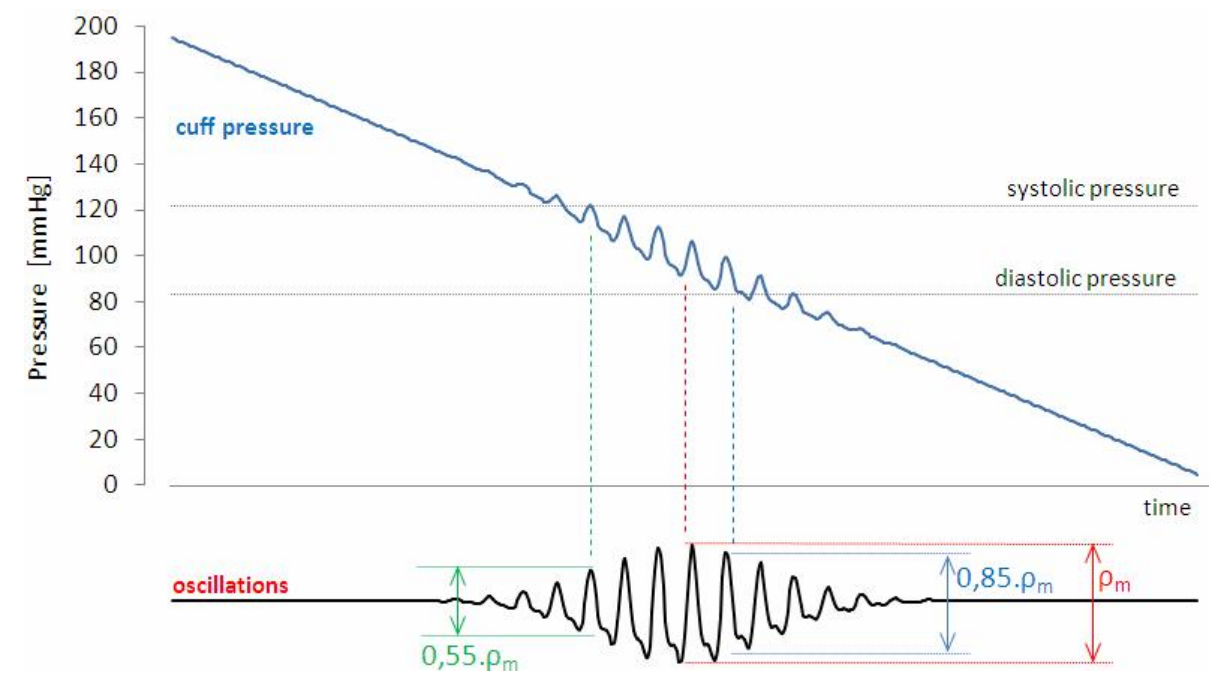

Fig. 1. Principle of calculation

\section{Realization}

The device is realized in form of printed circuit board with all appropriate components. The board is designed with distinctly separated function blocks, including several test pins for direct monitoring of inner raw signals with an oscilloscope. It enables to investigate all commonly inaccessible signals in detail.

The board can be controlled either via USB interface or manually. In case of remote control by computer, additional software operates the laboratory kit. However, manual control allows us to control inflating and deflating manually with a button and a potentiometer. In both operation modes, it is possible to sample signals and send them to a PC. For instance, it is possible to change the maximal pressure during inflating or the speed of deflating.

The board is equipped with an LCD display which shows the current state, the current pressure in the cuff and other detailed parameters. The PC application allows us not only to display the output values and configuration parameters but also to display the pre-processed signals and method for computing output values.

For better transparency, each block of the main board is marked with a label showing its function.

The additional software is designed to show separated signals from the cuff absolute pressure and correspondent oscillations. It is possible to record all measured data into a file or calculate blood pressure and the other hemodynamic parameters of vascular system. The device may be also remote controlled with the software. 


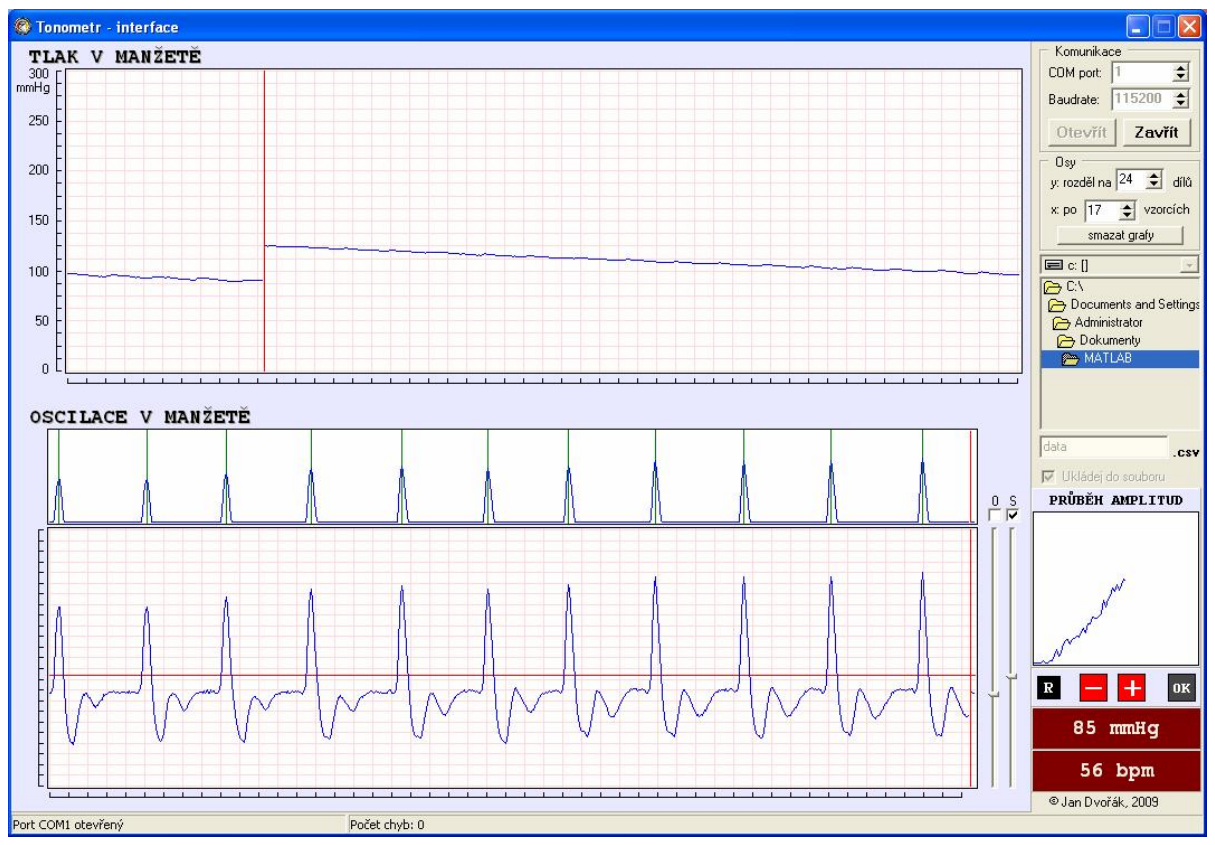

Fig. 2. Application interface

The main window of application for controlling oscillometer is shown in Figure 2. The upper curve is the absolute pressure in the cuff, the lower curve shows corresponding oscillations of pressure during reduction of pressure in the cuff.

After the recording of pressure signal the signal is parameterized (see Figure 3 ). The envelope of the signal and the amplitude of oscillations are obtained. Finally the SBP point (the amplitude of $55 \%$ of the maximum before the point of MAP, in Figure 3 labeled by asterisk) and the point of DBP (the amplitude of $85 \%$ of the maximum after the point of MAP) are calculated.

Measured signals can be stored to a PC for successive processing sample by sample. It allows analysis of oscillometric signals and easy development of new methods for oscillometric signal processing (e.g. improvement of methods for calculating the SBP, DBP and MAP values and the methods for obtaining parameters of cardio-vascular system from oscillometric signal).

\section{Conclusion}

The presented laboratory kit is a unique requisite which allows us to develop new methods of signal processing and calculations. The kit is also a unique tool for measurement of the hemodynamic parameters of vascular system.

Values of blood pressure and the other hemodynamic parameters can often adumbrate cardiovascular problems, apoplexy or internal organs damage. Therefore it 


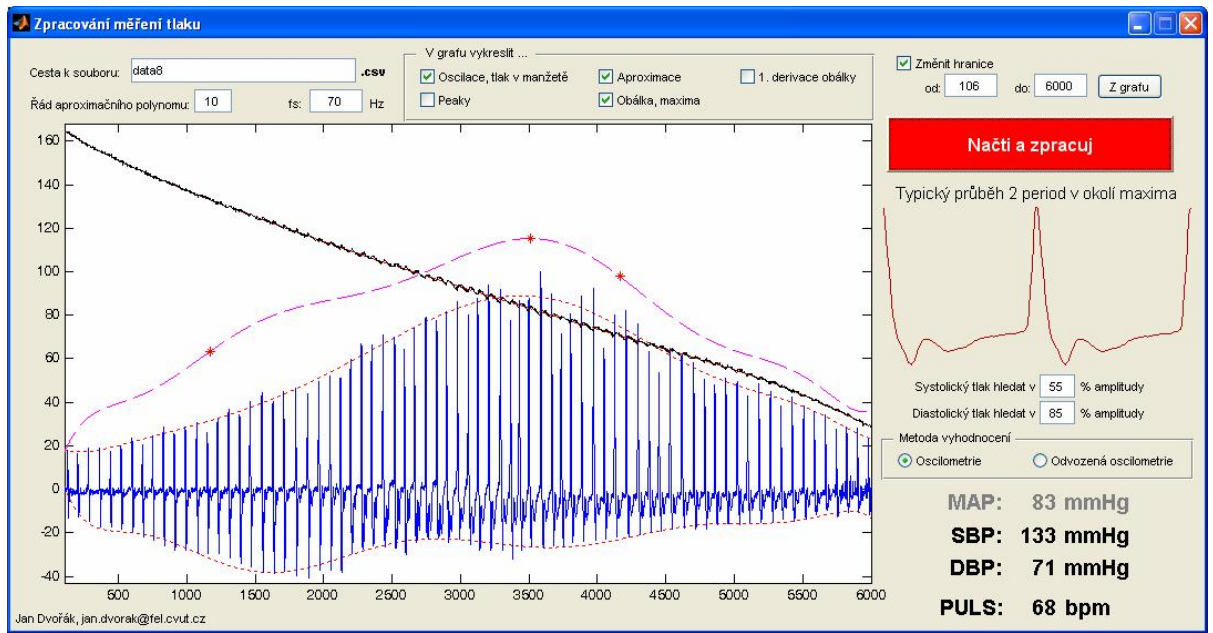

Fig. 3. Parameterization of pressure signal

is very important to know the mentioned values. Standard devices do not allow measuring these parameters, despite the principle of oscillometry method enables it.

Furthermore, the module can be used for recording of the raw signals to a PC, which extends the possible usage. This laboratory kit can be also used for studying how artifacts, size of cuff or speed of deflating can influence signals and results.

\section{Acknowledgement}

This work has been supported by the research program Media Lab of the Czech Technical University in Prague and the research program No. MSM 6840770012 of the Czech Technical University in Prague (sponsored by the Ministry of Education, Youth and Sports of the Czech Republic).

\section{References}

1. Oliver, J. J., Webb, D. J. Noninvasive Assessment of Arterial Stiffness and Risk of Atherosclerotic Events. Arteriosclerosis, Thrombosis and Vascular Biology (2003) 23, pages 554-566

2. Wilkinson, I. B., Cockroft, J. R. Estimation of central aortic pressure: shedding new light or clouding the issue. Clinical Science (2004) 106, pages 433-437

3. Dvořák, J.: Výukový modul elektronického tonometru s možností záznamu a zpracování měřných dat. In: Proceedings of the $8^{\text {th }}$ Czech-Slovak Conference "Trends in Biomedical Engineering" [CD-ROM]. Bratislava, 2009.

4. Webster, J. G.: Medical Instrumentation - Application and Design. Wiley, 4th edition, 2007.

5. Penhaker, M. a kol.: Lékařské diagnostické prŕístroje - učební texty, VŠB-TU Ostrava, 2004.

6. Rozman J. a kol.: Elektronické přístroje v lékařství, Academia Praha, 2006. 